\title{
An Overview of Chemical Process Design Engineering
}

\author{
David Mody, Queen's University, David.Mody@chee.queensu.ca \\ David S. Strong, Queen's University, strongd@appsci.queensu.ca
}

\begin{abstract}
The nature of Chemical Process Design Engineering requires that it utilize methods of design that sometimes differ from product design, yet clearly, many overlaps exist. This paper describes the general procedure for designing a chemical plant, the common design documents, and today's tools for achieving a chemical plant design. Parallels and differences between process and product design are highlighted.
\end{abstract}

\section{Introduction}

Design in its most simplistic viewpoint is composed of the following steps:

1. Determine the problem and its constraints

2. Generate potential solutions

3. Develop sufficient detail that solutions can be compared and eliminated

4. Implement the preferred solution

Product Design and Chemical Process Design often share the objective of producing a product for a commercial purpose. In many ways the two are similar, but process design, as typically taught in the universities, has historically emphasised the manufacture of a known product more than the development of a completely new product. It should be noted that, to the chemical process engineer the word 'product' is meant to encompass not only chemicals, but also energy or other commercially useful "things". A generic process can be described as follows:

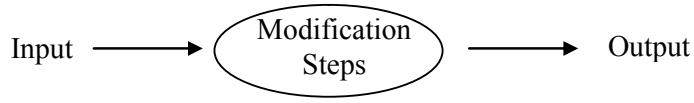

Figure 1. Generic Process

The invention of new chemical products (e.g. Nylon ${ }^{\circledR}$ or Lycra $\AA$ ) to suit specific end needs or properties such as strength, weight, colour fastness, abrasion resistance, high temperature capability, or flexibility, etc. is typically the role of the molecular/chemical designers who are usually located in chemistry laboratories and research centers. However, the design of the modification steps to generate the chemical product in production quantities is more firmly in the domain of the process design engineer. In the chemical industry the product and its manufacturing process are so intrinsically linked that these two roles sometimes blur into one 'research and development' person. However, as we shall see below, process design engineers sometimes find themselves in different situations, such as:

1. The Output is known and a desirable route to its production is to be designed, including selecting appropriate inputs.

2. The Inputs are known and a desirable output is required along with 1 .

3. The desirable properties are known and a product along with its manufacturing process is to be designed.

4. The inputs, outputs and route are known, but an optimization of the route is to be performed.

In either Product or Process Engineering, the primary objective of the design engineer is usually to produce something at the lowest possible cost, with the most commercially desirable attributes, and to do so in a way that meets all applicable laws and standards and ensures safety and protection of society.

In the realm of the process designer, the objectives can be open ended, such as producing a more environmentally friendly or safer stream, or to meet a legislative requirement. But, more commonly, the end product is known and the route to its production is being designed, which tends to make the design problem less open ended. Another example of an open ended design problem would be when the objective of a process is to make use of a waste stream in any manner possible, which may or may not, require changing it's molecular properties (i.e. convert it to a useful product, burn it to recover energy, or digest it using biological means). In such a situation, the feeds 
are defined and the product of the process is unknown. In either of these examples, there is a strong sense of the 'product' that will be produced and consumed, but this is not always the case.

Another potential situation for process design engineers is the optimization of a process. By its very nature, the objective of improving efficiency (less waste, less raw materials, less energy use, greater production rate, etc.), or improving safety, necessitates the use of creative thinking and engineering tools to satisfy the problem definition and constraints. In these situations, the final "product" may be performance criteria, and therefore the process itself becomes the product of the performance requirement. An analogy in "hard product" production would be improvement in the production process for higher throughput, lower scrap rate, higher quality, or lower cost.

Since the objectives of process and product design typically overlap, it follows that the engineering process to achieve the desired results should be common. In the next section some of the steps taken by the process engineer during the typical chemical plant process design will be discussed. The reader familiar with product design and/or manufacture is invited to draw comparisons with their own experience.

\section{The Steps of Chemical Process Design}

As with any engineering design problem, a goal is to eliminate non optimal solutions with as little "effort cost" as possible. This usually leads to an iterative, or "bootstrapping" design methodology that begins with a low level of detail in the solutions and progressively creates more and more detail of fewer possible solutions until an optimal one is found. During the design development, one of the key decision making tools is economic viability, and producing design information that assists in making that analysis is principal to any methodology. The process of design has the following goals:

Goal 1. Eliminate solutions with as little effort as possible.

Goal 2. Produce a financial estimate

Goal 3. Understand the risk that the process poses to society and the environment

Goal 4. Produce the documentation required to build the process.

"Text book" process design is commonly broken down into the following stages:

1. Problem Definition

2. Process Synthesis
(Multiple solutions are generated and discarded as quickly as possible to produce a small number of favourable solutions that are taken to more detail)

3. Process Design

(One or two most favoured solutions are developed in enough detail that reasonable financial analysis can be performed, safety and environmental issues can be identified and their risk understood.)

4. Process Analysis

(In this stage optimization of the conditions or equipment will be performed.)

Experience suggests that the steps of process design are intrinsically linked to the phases of how projects in the chemical process industry are executed, and to a smaller degree, the opposite is true. The rest of this paper aims to document those phases, and the products of design that chemical engineers are often involved in.

The following phases of a project are often used, with smaller projects combining some of the stages. The names may be different between companies but for the sake of simplicity we shall refer to them as:

\section{Front End 1 \\ Front End 2 \\ Front End 3 \\ Detailed Design \\ Construction \\ Start-up}

As will be discussed, the design progressively provides not only more detail about the facility so that it may be built and operated, but equally importantly, it provides progressively more accurate estimates of its capital, operating costs, and business risk for business planning purposes. Some steps have a strong emphasis on technical design, some provide essential quality control, others prioritize costs and project management, and some focus more on societal impact. All are elements of the "process design process." At the end of each of the first four stages, an opportunity is provided for the business team to review the financial/project risk or the changed business environment, and a decision is made to either proceed, delay, or cancel the project.

\section{Front End 1}

Depending on the nature of a project, there is a wide range in the amount of available initial information. If the project is a duplication of, or similar to a previous project, then the core process is probably well defined but the interfaces (conditioning of inputs, provision of utility services, storage, 
(un)loading, etc.) are less so. If the project will be dealing with a new product, then much less information would be available. Regardless, this stage begins with a statement of business objectives and possibly some general information about the actual chemical or product that will be produced, and/or the feedstock that is available.

A thorough analysis of the opportunity and its constraints is usually documented in something called "Basic Data". The Basic Data remains a living document until the point where a process flow diagram and the heat and material balance (discussed later) are finalized. Once considered complete, the Basic Data is said to be 'frozen' and provides the guidance to all of the designers throughout the life of the project.

The first process design step is to generate a series of possible solutions to the problem. The most simplistic representation of a process begins with a block flow diagram, which is distinguished by the fact that no real equipment is required to be documented. A simplistic example is below:

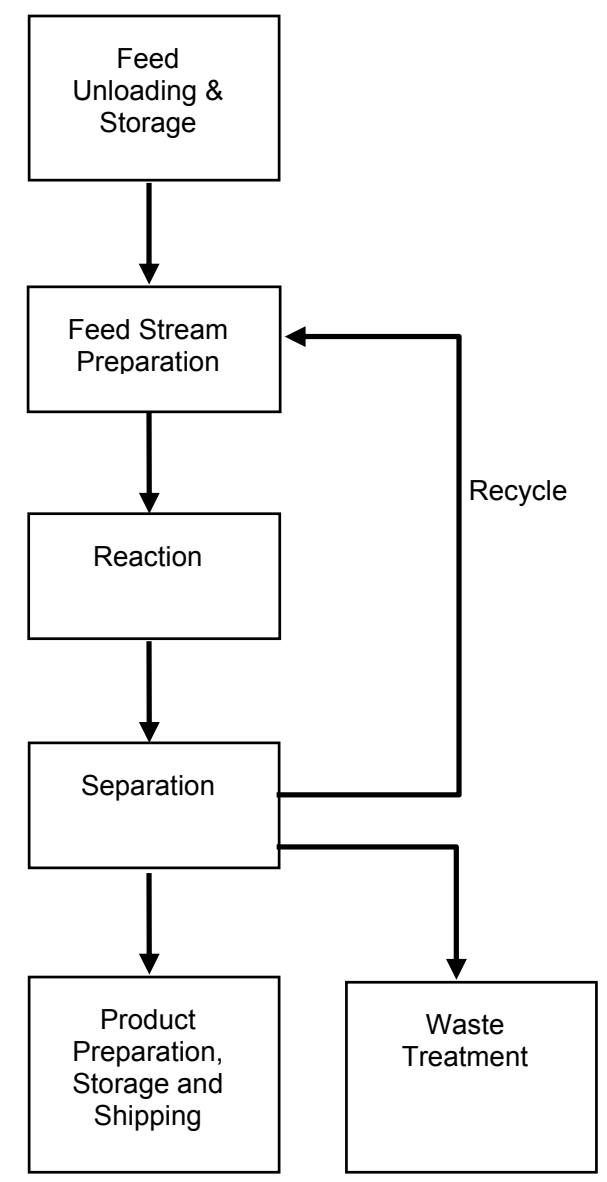

Figure 2. Block Flow Diagram
In a chemical process, the inputs and outputs are usually chemicals, and the modification step is usually some molecular change or bulk property change that takes place (e.g. a separation, a reaction, or a change in heat, size, etc.). The above diagram does not provide much more information than allowing the comparison in costs between raw materials and products. It does allow for a first pass at eliminating some of the possible solutions, for instance, where the inputs are more costly than the outputs.

How the chemical engineer "invents" or synthesizes these alternatives (which are often called the process topography) is an interesting topic. Historically, creative thinking and experience are used,. but the opportunity to use the product designer's toolkit such as TRIZ, brainstorming, creative problem solving, and others are all possibilities deserving of some consideration. An excellent general purpose reference text dealing with creating the process topography is Analysis, Synthesis, and Design of Chemical Processes [1].

A number of processes require a chemical reaction as part of the modification step(s). The choice of the reaction pathway often significantly affects the overall commercial, safety, and environmental aspects of the process, so it makes sense to show the major alternatives in a tree format with the reactions at the top.

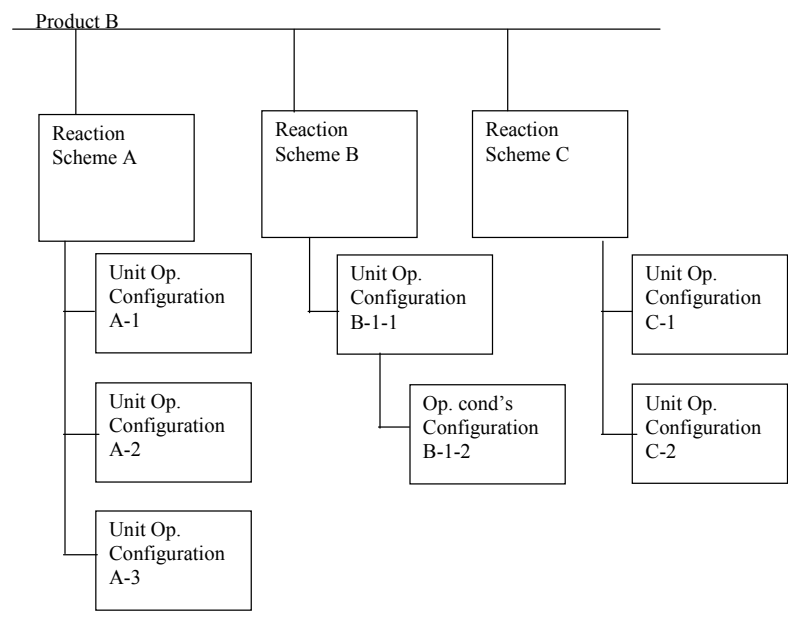

Figure 3. Synthesis Tree Diagram

The possibility of using a continuous or batch process should also be explored at this point.

One technique in process design is described in the book Products \& Process Design Principles [2]. They paraphrase the text from Process Synthesis [3] and describe the following steps: 
Table 1. Process Synthesis Steps

\begin{tabular}{|cl|l|}
\hline Synthesis Step & Process Operations \\
\hline 1. & $\begin{array}{l}\text { Eliminate } \\
\text { differences in } \\
\text { molecular types }\end{array}$ & Chemical Reactions \\
\hline 2. & $\begin{array}{l}\text { Distribute the } \\
\text { chemicals by } \\
\text { matching sources } \\
\text { and sinks }\end{array}$ & Mixing \\
\hline 3. & $\begin{array}{l}\text { Eliminate } \\
\text { differences in } \\
\text { composition }\end{array}$ & Separation \\
\hline 4. & $\begin{array}{l}\text { Eliminate } \\
\text { differences in } \\
\text { temperature, } \\
\text { pressure and phase }\end{array}$ & $\begin{array}{l}\text { pemperature, } \\
\text { change }\end{array}$ \\
\hline 5. $\begin{array}{l}\text { Integrate tasks; } \\
\text { that is, combine } \\
\text { operations into unit } \\
\text { processes and } \\
\text { decide between } \\
\text { continuous and } \\
\text { batch processing }\end{array}$ & \\
\hline
\end{tabular}

When multiple solutions remain, or if one must be carried to financial analysis, the next step in the design is to produce a model of the process. This model is documented in the format of a "process flow diagram" (PFD) along with accompanying heat and material balances (for discussion purposes, further reference to the PFD will also include a heat and material balance). The PFD provides the first glimpse at what equipment will have to be purchased, and what utilities or additional chemicals will be required to make the process work. A variety of software tools are available for accomplishing the task, such as Unisim, HYSYS, Aspen, and PRO II., but a common spreadsheet style computer program are also necessary to do the required process modelling.

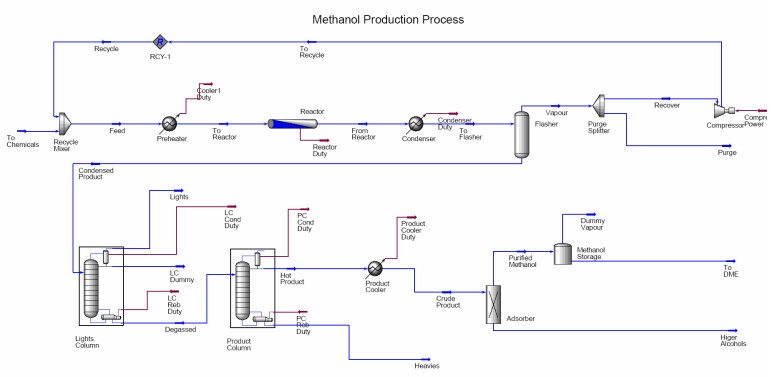

Figure 4. Process Flow Diagram
The Process Flow diagram shows the order of the Unit Operations (the equipment) and any recycle streams. What really distinguishes the PFD from the Block Flow Diagram is that all the flows, temperatures, pressures, etc., that enter, or exit a piece of equipment, are defined. This information largely specifies the required performance of the equipment. However, the process flow diagram is not a perfect representation of what the real life process will look like. Similar to the Block Flow diagram, the PFD, like all models, may contain many simplifications. In particular, the PFD does not typically include effects such as gravity, or pressure drop through equipment. Similarly, the PFD may illustrate a single operation that will require two pieces of equipment, or it may show an operation (e.g. a mixer) which probably has no equivalent piece of equipment. In short, judicious engineering judgment must be used to translate the process flow diagram into an actual working process that will be documented by the Piping and Instrumentation Diagram (P\&ID). Despite the simplifications or assumptions, there is wealth of information provided by the PFD and material balance, such as the phase (i.e. vapour or liquid, 2 phase), flow rate, the temperature, the pressure, and the molecular compositions that enter and exit the individual operations. In addition, in the case of a distillation column, the same information is also available for the tray to tray internal column operation. A short excerpt of the type of information available from a commercial simulator package (UNISIM) is shown below:

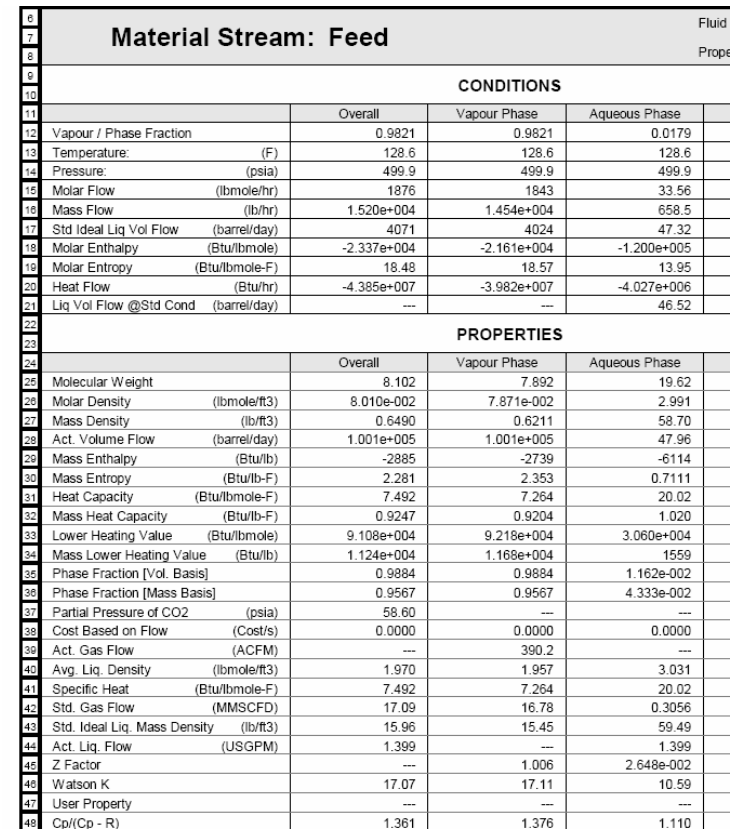




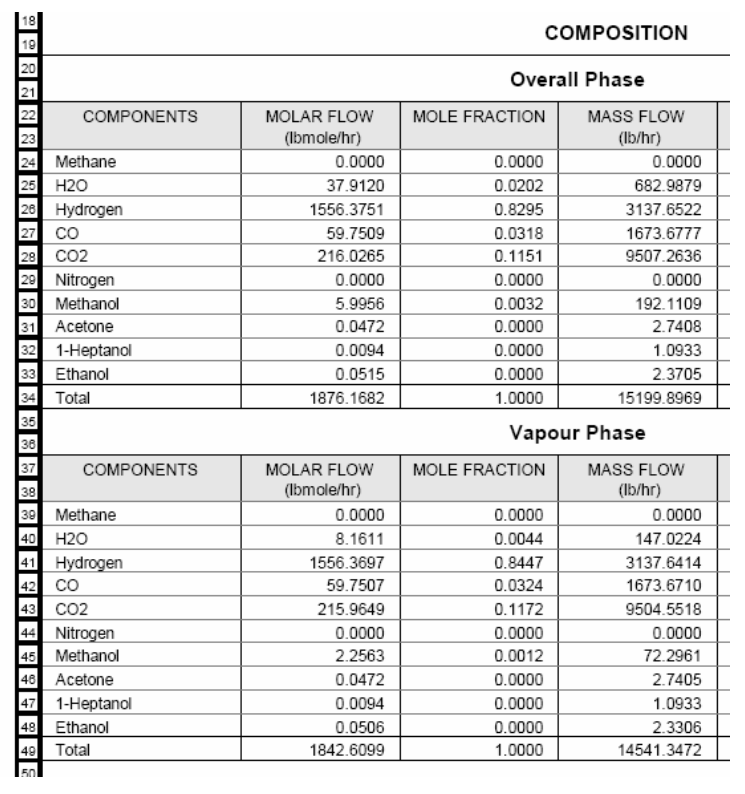

Figure 5. Simulator Information Example

Not surprisingly, the PFD and the material balance are closely guarded secrets by most corporations.

At the stage in a project where the PFD has been generated, a majority of the future plant costs and safety/environmental risks are locked in. A Process Hazards Review sets the direction of subsequent reviews and, which addresses the major hazards of the chemicals and operating conditions, is performed. The PFD becomes a pivotal document in determining the economics of any particular process. Usually, with some minor additional engineering, and with the selection of proper materials of construction enables a reasonably accurate financial analysis $(+/-30 \%$ of the capital costs) can be performed, which includes the raw materials, the utilities and the plant capital costs. This provides a perfect opportunity to eliminate all but a very few of the possible solutions. It would be common to end this phase with a business review of the selected options. The documents most likely to be discussed at such a review would be the capital cost estimate, the overall project financials and risk (NPV, IRR, etc.), a project schedule, and a preliminary analysis of the process, environmental, or technical risks that might impact the viability of the project. Should the review be favourable, the project moves on to the next project stage of engineering.

\section{Front End 2}

For small or simple projects, this step is likely to merge with either the previous or the next step. The objective of this step is to further define the equipment and to begin to define other ancillary costs for the purpose of preparing a more accurate capital cost estimate and financial analysis.

The previous stage approved the go-ahead for further analysis. Therefore, there are still some unknowns. There are a multitude of questions that may need to be answered before a better design of the plant can be produced. Many of these questions are a result of simplifications or assumptions that have resulted during the process flow diagram stage. Often the unknowns are in the technology and can not be resolved without running the plant. This would be a suitable time to build a prototype (pilot plant), or run test work on an existing process to resolve issues, such as side reactions, that might build up in the process or cause premature failure due to corrosion, or more simply to confirm the kinetics for reactor sizing. A final material balance may be prepared based on the input from the pilot plant or test work. Further design may proceed either in parallel with the pilot plant or iteratively with its design and operation. When the $\mathrm{PFD} /$ material balance is deemed to have no further issues that must be resolved, the next step is to prepare the Piping and Instrumentation Diagrams (P\&ID's).

P\&ID's are key to any further design. These drawings describe how the plant will look and operate better than any single other document. It is at their generation that all other engineering disciplines (electrical, instrumentation, civil, mechanical, piping, HVAC, fire protection) can begin their preliminary design. Now the accuracy of the cost estimate is notably improved because reasonably accurate estimates of material quantities can be developed.

The P\&ID is developed in stages and remains a living document until construction begins. At this stage in the project, all the equipment (including spares), the instrumentation, and the piping will be shown. Depending on the accuracy of the estimate that is intended to be developed, the pipe codes, insulation, and requirements for tracing will also be shown. (Alternately, these items may be left until stage 3 or detailed design). Since this is still a preliminary stage of design, if there is an existing plant or parts that are identical, the P\&ID's may be merely copied. Extensive detail is added in later stages of design and the final version of the P\&ID's is ready only prior to construction.

The first draft of the P\&ID's is an opportunity to review the design with a variety of stakeholders (operators, maintenance people, plant engineering, etc.) and a thorough review of the drawings is well worth the time commitment to avoid changes in the construction or start-up phase. 


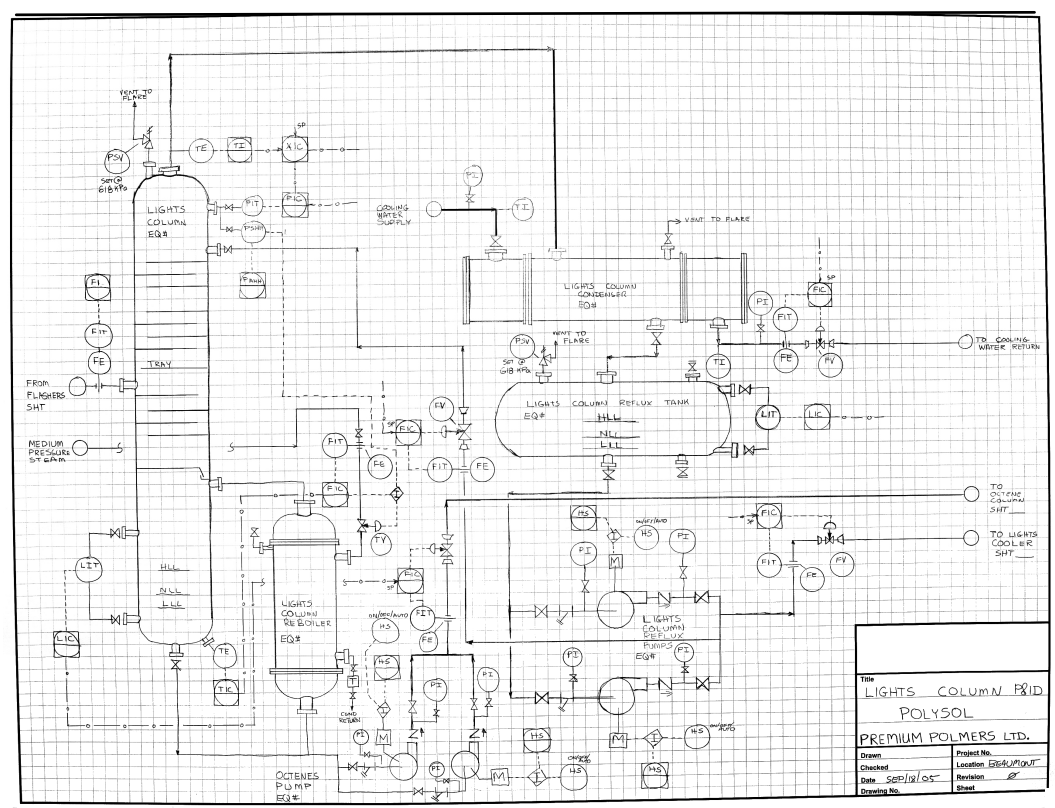

Figure 6. Early Stage P\&ID Example

Equipment data sheets are usually the next item to be developed. The purpose of the Data Sheets, as they are often called, is to provide sufficient information in order to be sent to vendors for firm quotes. The data sheets are usually initiated by process engineers using information in the heat and material balance, along with standard engineering calculations and guidance from either standards or codes. Basic data or company engineering standards will likely supplement details of the equipment design. Mechanical and/or electrical and instrument engineers provide further detail to the data sheet and usually produce a specification ready for quotation by vendors. In all likelihood, at this stage, only the major equipment that requires quotes (or must be ordered very early in the project schedule) will be developed. Prices for minor pieces of equipment may be obtained from recent projects or estimated by the design team.

Given a P\&ID and a set of equipment data sheets, a reasonable attempt at the equipment layout can begin. This starts with a plan view and could possibly extend to elevations or a concept 3D model. A model would not normally be expected at this stage of the design and certainly a detailed one would be rare. A follow-up to the initial Process Hazards Review that includes some analysis of the information contained on the P\&ID's would also be performed.

Since all utilities should be defined at this stage. a thorough analysis of existing site infrastructure versus that needed by the project can be performed, and additional offsite requirements may be added to the project estimate (e.g. steam plants, electrical substations or cogen units, compressed air systems, backup generators, etc.). The remaining plant costs such as loading, unloading, raw material and product storage, cooling and fire water, waste treatment facilities, control rooms, laboratories, maintenance shops, and offices, must be reviewed and included in the capital estimate.

The P\&ID affords the first opportunity for the controls group to determine the cost of computer control hardware, control room requirements and to prepare a quantity estimate of the overall control hardware required for operating the plant.

Although it requires additional engineering costs, this is the time where sufficient design detail is defined that a serious critique of the environmental and safety issues, technical issues and operating/capital costs can and should be performed. If necessary, significant changes to the design can be implemented at this point with little impact to the overall cost of the project. Later in the project, significant changes are so costly to implement (due either to schedule extensions, reengineering, or reconstruction costs) that it may not be feasible to make them. Thus, from this point onwards, a change policy is often enforced to ensure all costs are properly considered before a deviation from the original design is approved.

All relevant information is assembled into a "Scope of Work" document. The information contained within this document should allow for a cost estimate in 2 plus/minus $10-20 \%$ range, which could be sufficient to make an informed decision to either halt the project, recycle the design with updated business criteria (i.e. reduce the capital cost, have the plant produce a different product mix etc.), or give it a very high 
probability of proceeding through the further stages of development (which are quite costly in terms of engineering expense). This decision is officially not made until the Front End 3 stage, but in reality, the business team's decisions are usually made at this point. Because of this, some equipment that has long delivery times may be identified, and detailed engineering specifications sufficient for their purchase are prepared.

\section{Front End 3 - Construction Cost Estimate}

Approval to proceed with this stage is essentially a commitment to begin spending capital money on the project. Many of the design documents are considered to be capital for tax depreciation, and if it's deemed highly advantageous, some long lead items that were identified in the previous phase are ordered

The objective of this phase of the project is to produce a cost estimate with $+/-5$ to $10 \%$ accuracy. In order to accomplish this level of accuracy, material requirements or "take offs" (eg. tons of concrete, $\mathrm{ft}$ of cable, ft of piping. etc.), and man hours for installation must be generated. Modern 3D plant modeling software is database driven and produces the necessary material take offs for the piping and civil engineering groups. It would be common to produce a rough $3 \mathrm{D}$ model, complete with preliminary piping, at this stage. Some of the structural analysis would also be completed. The process engineer will have to provide some reasonably accurate line sizes as input to the piping model. Similarly, weights of equipment and sizes must be available for the structural group.

To produce the 3D piping model, P\&ID's and quality control / design tools called the "piping line list" and the "application index" must be generated. The Piping Line List and the Application Index document every pipe in a plant, and list the design pressures, temperatures, materials of construction, and other critical properties. All three of these supporting documents are usually submitted to pressure vessel/piping regulatory agencies during the detailed design or construction phase.

The 3D plant modeling software removes the additional step of creating isometric drawings, while at the same time integrates other disciplines design work in a way that flags interferences (e.g. between steelwork and piping) from occurring. Typically, the 3D models are not fully completed until the Detailed Design Phase. Since the piping material take offs are automatically generated, the model must be completed to a reasonable level of accuracy for the purpose of preparing the capital estimate.

Process Hazard Reviews based on the documentation provided to date are performed to ensure adequate levels of protection against possible unexpected events, and that there are no significant unknowns that could affect the estimate's accuracy.

Normally a preliminary "constructability review" is performed, which provides valuable insight into the plant design and schedule to ensure the minimization of costs during the construction phase. One example of this would be the coordination of the civil/structural installation schedule with the equipment deliveries to minimize the size, number and duration of crane rentals.

Significant legal documentation such as environmental permits might be started in this phase, but they are not usually submitted for approval until all design details are complete. All the above documents, including a schedule for completing the project, are added to the Scope of Work document package.

A revised financial estimate for the project is generated, and is then compared to the cost estimate created in Front End II. Any substantial difference will be carefully scrutinized and a final financial analysis for economic viability is performed. Using all of this information, a business review cycle is undertaken, culminating in the decision to proceed, delay/recycle or cancel the project.

\section{Detailed Design}

The detailed design phase produces information packages that describe the plant in sufficient detail for construction to begin. Usually the initial civil engineering begins as early in this phase as possible. An estimate is also produced but its purpose is to control the construction phase and ensure there are no omissions from the Front End 3 phase, rather than to provide significant additional financial analysis. The contracts to build the equipment are issued in this phase, with the expectation of using the detailed engineering drawings from the vendors to complete the piping, electrical and instrumentation design.

Upon receipt of the construction bids, a final review of the costs is completed and approval by the owner, and the order to proceed with construction, would be given.

Piping design is usually completed through the use of 3D models. Detailed reviews of the facility are carried out with the internal stakeholders (operations, maintenance, and engineering) to provide feedback. Isometrics drawings can now be prepared from the 3D model for inclusion into the piping construction packages. Process designers must check that any assumptions made about the piping during equipment design are in fact true. They must also finalize the relief valve sizing from the isometric drawings produced from the $3 \mathrm{D}$ models. Site preparation and 
initial civil work can begin if funds have been approved (typical of a fast track project).

An important consideration is that the environmental legislative groups normally require completed design documents prior to their review. Their approval is required prior to the beginning of construction and their review of the project can take substantial periods of time. Therefore, finalizing any documents required for their review is given priority so as to avoid construction delays.

When a P\&ID, a material balance, and if possible, the 3D model are available, further Process Hazards Reviews are completed to ensure all hazards have been identified and adequate levels of protection are provided. This will ensure the risks are acceptable, hopefully with minimal impact on the design, costs and schedule.

A "constructability review" will occur in this phase in order to ensure the design is optimized for cost effectiveness.

\section{Construction}

As the names implies, this phase involves the actual construction of the plant. In fast track projects, some of the site preparation, including items such as building foundations and some of the building steel will be installed in the detailed design phase. However, the majority of the craft labour will occur in this step. The process engineer is not normally significantly involved in this stage.

When construction is complete, a final process hazards review of the facility is completed to ensure that all recommendations previously made in safety reviews have been implemented, and that no additional hazards are present as a result of the construction. Prior to Commissioning and Start-up, the process engineers contribute to the writing of operating procedures, which, in fact, is the "user manual" for the plant.

Given the complexity of a chemical process plant, it is fairly common to have some minor glitches during start-up. Typical examples would be motors turning in the wrong direction and infant mortalities in the electronics. However, more significant problems may appear due to inadequate information in the design (e.g. phase separations, or unexpected physical properties) Process design engineers are usually on hand to ensure the intent of the design is met, and to check performance of the plant against expectations as described in the Basic Data (the document that was initiated in the Front End 1 phase). At this time, operating procedures may be rewritten as a more complete picture of how the plant will perform becomes clear.
Once the plant has met functionality requirements, it is turned over to operators employed by the owners of the facility. The final phase is a wrap up session to discuss the overall project, with the intended outcome being "lessons learned" that can be applied to the next project

\section{Summary Comments}

As can be observed from the preceding discussion, there are similarities between product and process design. The level of "design process" similarity undoubtedly depends on many factors, not the least of which is to what kind of "product" the chemical process design is compared to. However, the general progression of the chemical process design, with the ever-growing documentation/specification package, considerations for cost, safety, and regulatory compliance, creative thinking, idea selection, and so on, appears very much like a progressive "concurrent product design" process, where both product and it's manufacturing process and equipment are developed concurrently by a cross-disciplinary integrated team. Although output and scale may be different, it would reinforce the notion that to a great degree, the "design process" is generic across the field of engineering.

\section{Acknowledgements}

The authors gratefully acknowledge supporting funding from the Natural Science and Engineering Research Council of Canada (NSERC), through their chairs in Design Engineering program.

\section{References}

1. Turton, Baille, Whiting, Shaeiwitz Analysis, Synthesis, and Design of Chemical Processes (2 ${ }^{\text {nd }}$ Ed 2003).

2. Seider, Seader, and Lewin Products \& Process Design Principles, (2004).

3. Rudd, Powers, and Siirola, Process Synthesis (1973) 